\title{
Enhancement of Voltage Stability in Power System Using Unified Power Flow Controller
}

\author{
Pinki Yadav "P.R.Sharma ${ }^{*}$, S.K.Gupta ${ }^{\#}$ \\ ${ }^{\#}$ Rawal Institute of Engg.\& Technology, Faridabad,Haryana \\ "YMCA University, Faridabad,Haryana \\ ${ }^{\#}$ EE Department,DCRUSTM, Sonepat,Haryana,India
}

\begin{abstract}
Voltage instability is one of the phenomenons that could happen in a power system due to stressed loading condition. The result would lead to the occurrence of voltage collapse which is nothing but the total blackout. Therefore voltage collapse possibilities and predictions are important in power system planning and operation so that the occurrence of voltage collapse due to voltage instability could be avoided. This paper presents a methodology of fast voltage stability index (FVSI) to identify the critical lines and buses to install the FACTS controllers. The line that gives FVSI value close to one will be taken as the most critical line corresponding to the bus, simulation results by using PSAT Software for the IEEE-14 bus system shows the location of UPFC in a particular line connected to the most critical bus to maintain the stability of the system.
\end{abstract}

Keywords: Voltage Stability, FVSI, UPFC, PSAT software

\section{INTRODUCTION}

Voltage stability, now a days is one of the most important research area in the field of electrical power system with the increased loading and exploitation of the power transmission system. Due to improved optimized operation the problem of voltage stability and voltage collapse attracts more and more attention [1-2]. Voltage collapse can take place in system or subsystem state [1]. The problem of voltage collapse may be simply because of the reactive power or by an excessive absorption of reactive power by the system itself. The continual increase in demand for electrical power has forced utility companies to operate their systems closer to the limits of instability. In this paper voltage stability analysis by using new line stability index (FVSI) [3]. The line stability indices are evaluated for each loading condition and line outage. The values of lines stability index would indicate the voltage stability condition in power system for particular load demand. Line stability indices values which approach 1.00 imply that the power system approaches its voltage stability limit. Voltage stability index based in normal load flow solution for online applications varies from 0 (no load of system) to 1 (voltage collapse) the bus with highest index value indicates the most vulnerable bus in the system and hence this method helps in identify the week areas in the system needing critical reactive power support.

FACTS controllers are used to regulate active and reactive power by their fast control characteristics and continuous compensating capability. By controlling the electrical parameters of the network under normal and abnormal conditions FACTS controllers improve the stability without generation rescheduling or topological changes [4-5]. Cost of the FACTS controllers is a major concern so it is important to find the location of these controllers. The location of FACTS controllers is identified by FVSI with PSAT software is used to find the settings of the FACTS Controllers. The most comprehensive devices that emanated from the FACTS technology are the unified power flow controller (UPFC).

For the last few years, the focus of research in the FACTS area is mainly on UPFC. This has resulted in many useful contributions in the areas of modelling of UPFC. However to achieve the good performance of UPFC in vertically integrated system but little attention has been devoted to increase the stability of the system. In this paper the selection of the best possible location for installation of an UPFC is carried out with an objective of enhancement the voltage stability of the IEEE-14 bus system using PSAT (power system analysis Toolbox) software [7].

\section{Principle Of Operation Of UPFC}

The UPFC is the most versatile FACTS controller developed so far, with all encompassing capabilities of voltage regulation, series compensation and phase shifting. It can independently and very rapidly control both real and reactive power flows in a transmission line. It is configured as shown in Fig 2.1 and comprises of two VSC's coupled through a common DC terminal. One VSC- converter 1- is connected in shunt with the line through a coupling transformer, the other VSC - converter 2- is inserted in series with the transmission line through an interface transformer. The DC voltage for both converters is provided by a common capacitor bank. The series converter is controlled to inject a voltage phaser Vs, in series with the line, which can be varied from $0^{\circ}$ to $360^{\circ}$. In this process, the series converter exchanges both real and reactive power with the transmission 
line q`. Although the reactive power is internally generated /absorbed by the series converter, the real-power generation/absorption is made feasible by the DC energy storage device-that is, the capacitor [5]. The shuntconnected converter 1 is mainly used to supply the real power demand of converter 2 , which it derives from the transmission line itself. The shunt converter maintains constant voltage of the DC bus. Thus the net real power from the $\mathrm{AC}$ system is equal to the two converters and their coupling transformers. In addition, the shunt converter functions like a STATCOM and independently regulate the terminal voltage of the interconnected bus by generating /absorbing a requisite amount of reactive power.

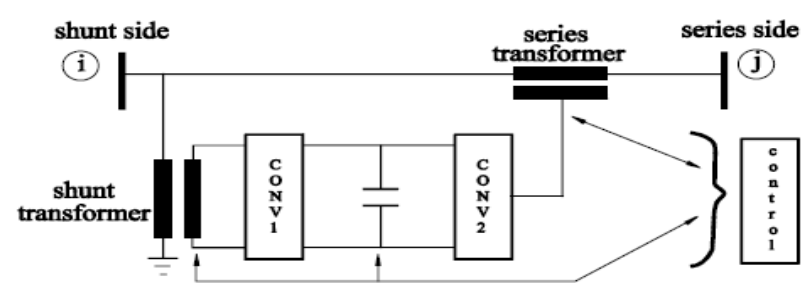

Figure1: Block Diagram of UPFC

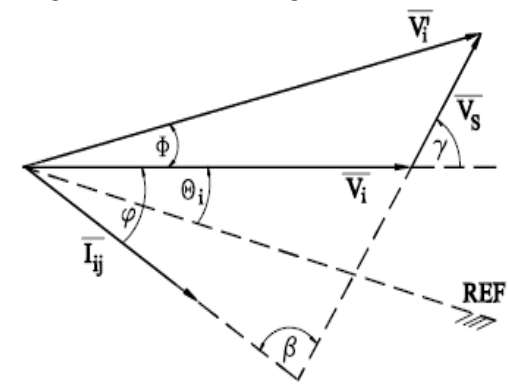

Figure 2: Phasor Diagram of UPFC

Where:

$$
\begin{aligned}
& \quad V_{i}^{y}=\overline{V_{i}}+V_{s} \\
& r=\frac{V_{i}}{V_{s}}, \\
& \text { Where } 0 \leq r \leq r \max \text { and } 0 \leq y \leq 2 \pi
\end{aligned}
$$

\section{Identification of Critical Lines and Buses}

The Fast Voltage Stability Index (FVSI) is used to identify the critical lines and buses. The characteristics of the FVSI are same with the existing techniques proposed by Moghavemmi et al. Whereby, the discriminate of quadratic equation is greater than or equal to zero. The maximum threshold is set to unity as the maximum value beyond which this limit, system bifurcation will be experienced.

\section{A. FVSI Formulation}

The FVSI is derived from the voltage quadratic equation at the receiving bus on a two-bus system. The general two-bus representation is illustrated in Figure 1.

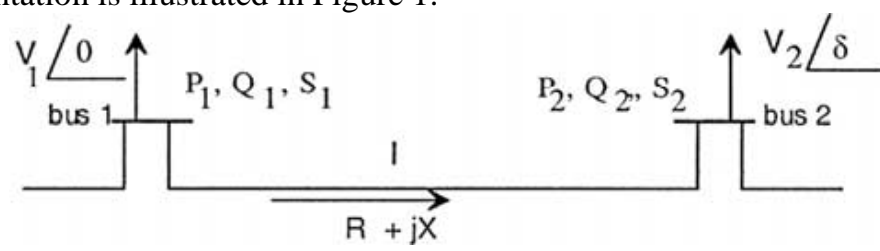

Figure 3: Two -bus power system model

$\mathrm{V}_{1}, \mathrm{~V}_{2}=$ Voltage on sending and receiving buses

$\mathrm{P}_{1}, \mathrm{Q}_{1}=$ active and reactive power on the sending bus

$\mathrm{P}_{2}, \mathrm{Q}_{2}=$ active and reactive power on the receiving bus

$\mathrm{S}_{1}, \mathrm{~S}_{2}=$ apparent power on the sending and receiving buses

$\delta=\delta_{1}-\delta_{2}$ (angle difference between sending and receiving buses) 
The line impedance is noted as $\mathrm{Z}=\mathrm{R}+\mathrm{jX}$ with the current that flows in the line is given by:

$$
I=\frac{\mathbb{R}_{1 \Delta D}-N V_{2 \alpha I}}{R+j X}
$$

$V_{1}$ is taken as the references, and therefore the angle is shifted into 0 . The apparent power at bus 2 can be written as:

$$
S_{2}=\mathbb{V}_{2} \mathrm{I}^{*}
$$

Rearranging (2) yields:

$$
\begin{aligned}
& I=\left(\frac{S_{2}}{V_{2}}\right) \\
& \frac{P_{2}-j Q_{2}}{W_{2}<-6}
\end{aligned}
$$

Equating (1) and (4) we obtained:

$V_{1} V_{2} \angle-\delta-V_{2}^{2} \angle 0=(R+j X)\left(P_{2}-j Q_{2}\right)$

Separating the real and imaginary parts yields:

$V_{1} V_{2} \cos \delta-V_{2}^{2}=R P_{2}+X Q_{2}$

$V_{2}^{2}-\left(\frac{R}{\pi_{i j}} \sin \delta+\cos \delta\right) V_{1} V_{2}+\left(X_{i i}+\frac{R^{2}}{Z_{i j}}\right) Q_{2}=0(7)$

$-V_{1} V_{2} \sin \delta=X_{i j p} P_{2}-R Q_{2}$

Rearranging (7) for $\mathrm{P}_{2}$ and substituting into (6) yields a quadratic equation of $\mathrm{V}_{2}$ :

$$
V_{2}^{2}-\left(\frac{R}{x_{i j}} \sin \delta+\cos \delta\right) V_{1} V_{2}\left(X_{i j}+\frac{a^{2}}{x_{i j}}\right) Q_{2}=0
$$

To obtain the real roots for $\mathrm{V}_{2}$, the discriminate is set greater than or equal to ' 0 '; i.e.

$$
\begin{aligned}
& {\left[\left(\frac{R}{x_{i j}} \sin \delta+\cos \delta\right) V_{1}\right]^{2}-4\left(x_{i j}+\frac{R^{2}}{x_{i j}}\right) Q_{2} \geq 0} \\
& \frac{4 z^{2} Q_{2} X}{V_{1}^{2}(R \sin \theta+x \cos a)^{2}} \leq 1
\end{aligned}
$$

Since $\bar{\delta}$ is normally very small, then

\section{$\delta \approx_{0, R} \sin \delta \approx 0$ And $X \cos \delta \approx X-$}

Taking the symbol ' $i$ ' as the sending bus and ' $j$ ' as the receiving bus, FVSI can be defined by

$$
\text { FVSIij }=\frac{4 z_{i j} 2 Q_{j}}{V_{i j} 2 X_{i j}}
$$

Where: $\mathrm{Z}=$ line impedance

$\mathrm{Xij}=$ line reactance

$\mathrm{Qj}=$ reactive power at the receiving end

$\mathrm{Vi}=$ sending end voltage

The value of VSI that is evaluated close to 1.00 indicates that 
the particular line is closed to its instability point. Therefore, VSI has to be maintained less than 1.00 in order to maintain a stable system.

\section{B. Identification of Critical Lines and Buses by Voltage Stability Analysis}

PSAT Software is used to find the voltage stability index. The assumption of this procedure for the implementation of this index methodology as follows:

Load buses are selected one at a time

- Voltage Stability Index is computed with an increase in reactive power gradually at chosen load

- Bus until the load flow solution fails to give result when keeping the real power remains constant.

- Voltage Stability Index of every line in the system is computed with an assumption that the real and powers loading of all other buses remain constant.

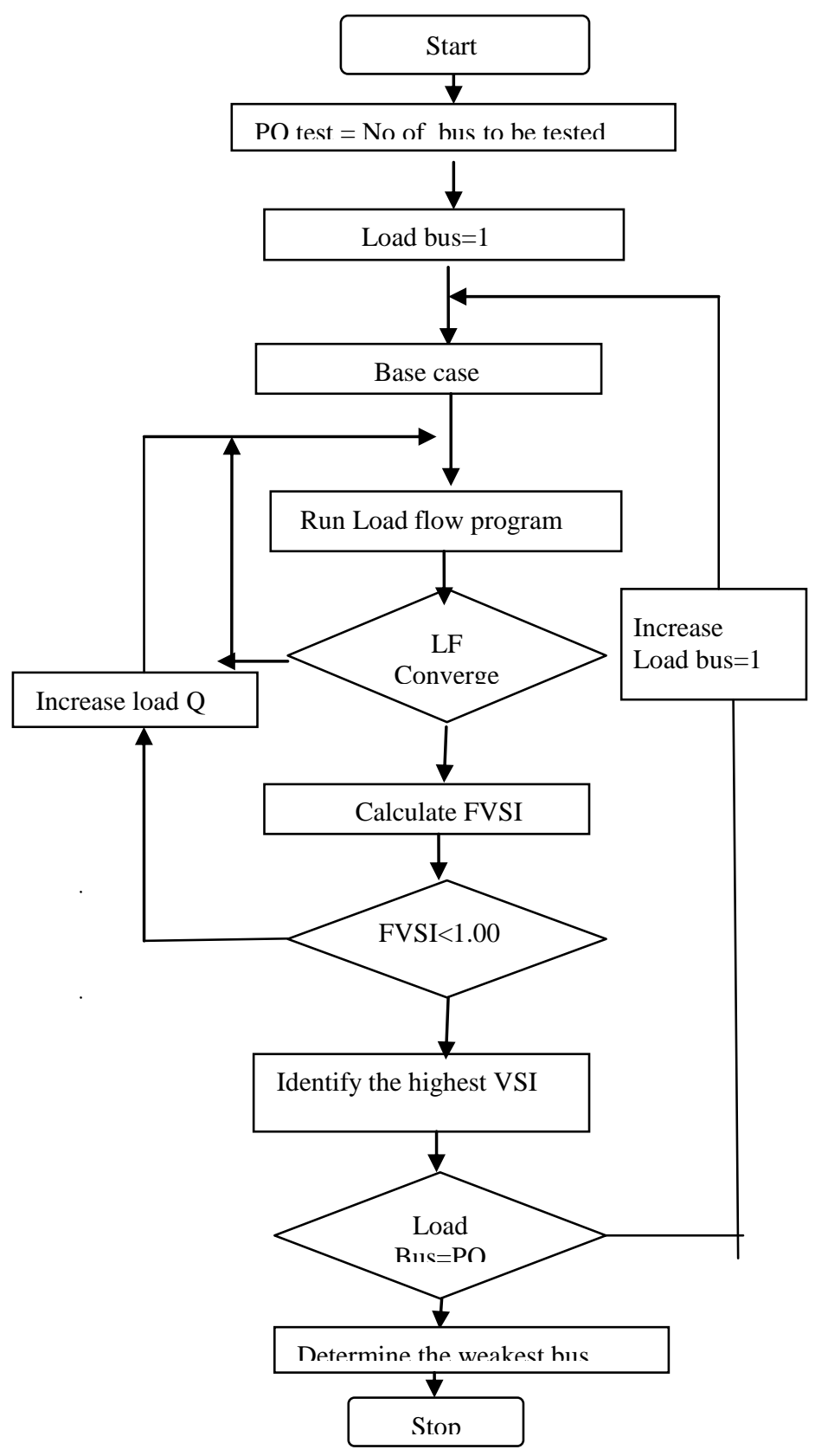

Figure4: Procedure for Voltage Collapse Predication 
A. Introduction

\section{Simulation Results}

Simulation studies were done for different scenarios in IEEE-14 bus System. Seven different scenarios are considered:

Scenario 1: Power system normal operation (without FACTS devices installation)

Scenario 2: One UPFC is installed on line 12-13 at Load Bus12

Scenario 3: One UPFC is installed on line 9-14 at load Bus 9

Scenario 4: One UPFC is installed on line 9-10 at load Bus 9

Scenario 5: One UPFC is installed on line2-4 at load bus 4

Scenario 6: One UPFC is installed on line2-5 at load bus 4

Scenario 7: One UPFC is installed on line5-4 at load bus 4

a) Simulation without FACTS Devices

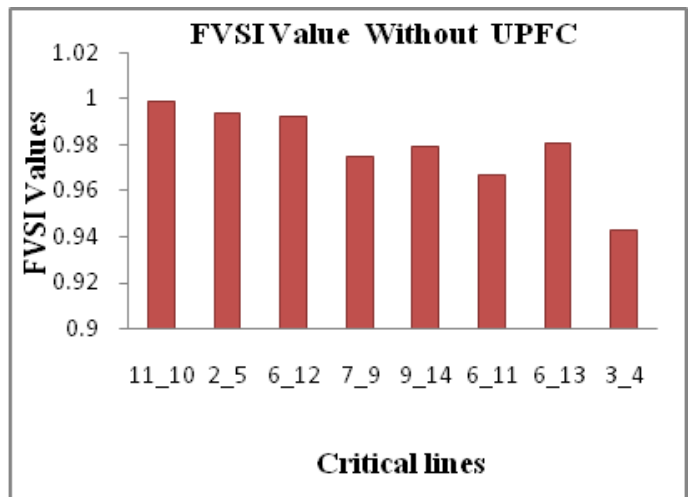

Figure 5

b) Simulation with UPFC installed on line 12-13 at Load Bus 12

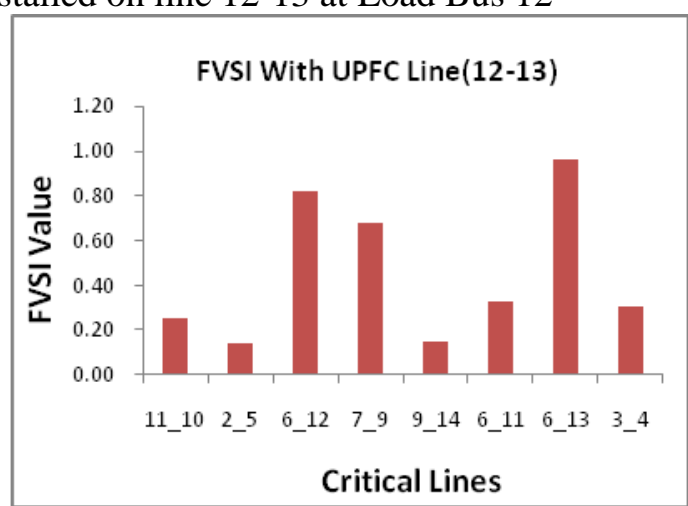

Figure 6

c) Simulation with UPFC installed on line 9-14 at load Bus 9 


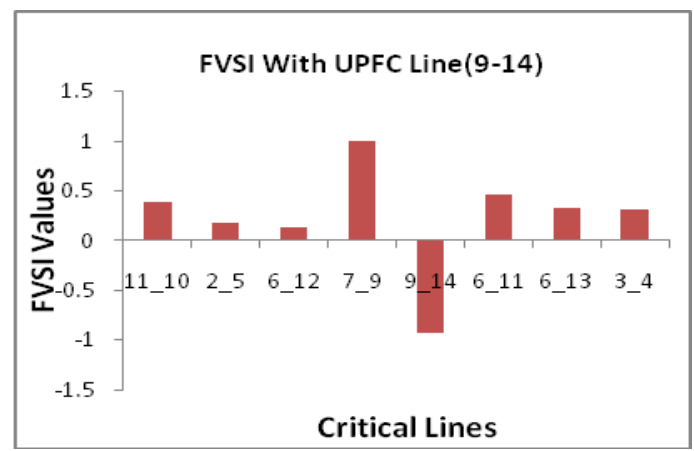

Figure 7

d) Simulation with UPFC installed on line 9-10 at

Load Bus 9

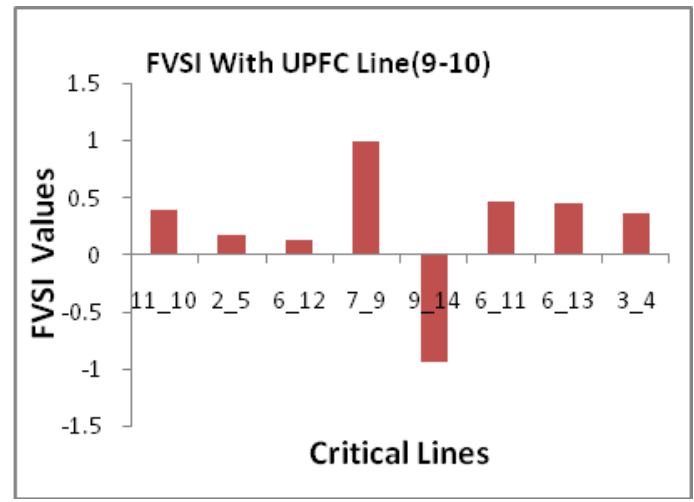

Figure8

e) Simulation with UPFC installed on line2-4 at load bus 4

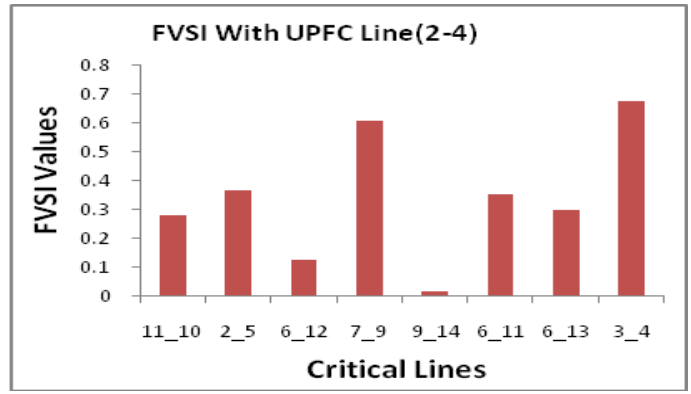

Figure 9

f) Simulation with UPFC installed on line5-4 at load bus 4

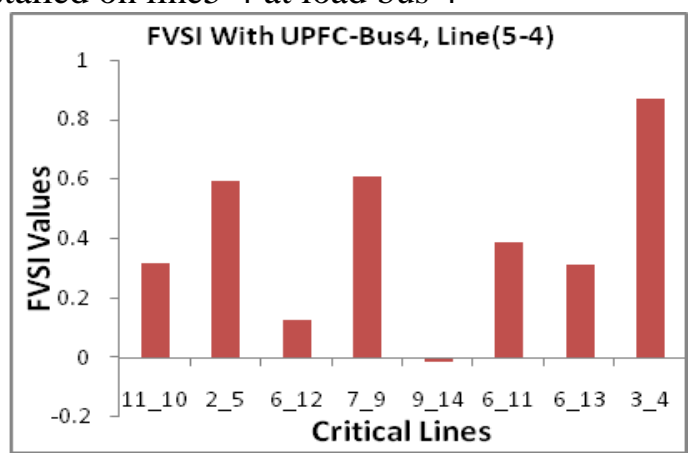

Figure10

g) Simulation with UPFC installed on line2-5 at load bus 4 


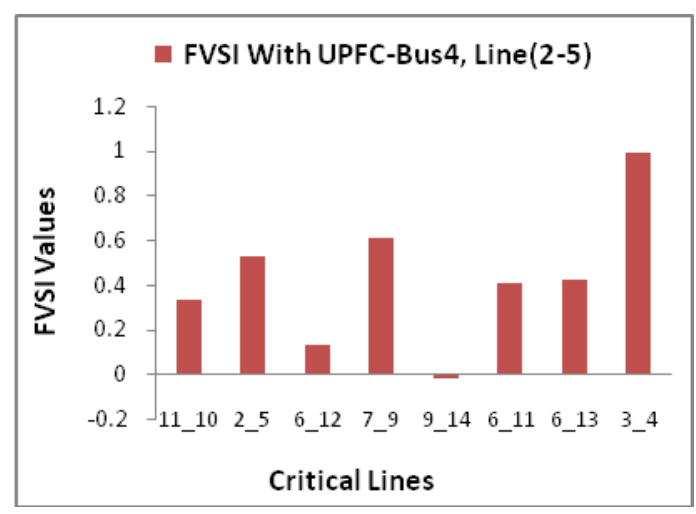

Figure 11

From Figure 5, it is observed that eight critical lines 11-10, 2-5,6-12,7-9,9-14,6-11,6-13 and 3-4 are noted with highest FVSI Index(unity) in IEEE-14 bus system and make the system unstable without UPFC.Figure 6 shows the location of UPFC on line 12-13 improves the FVSI index of the eight critical lines but line 6-13 shows the critical value near to one. Figure 7shows the location of UPFC on line 9-14 improve the FVSI index of the eight critical lines but line 7-9 again shows the critical value near to one.

Figure 8 shows the location of UPFC on line 9-10 improve the FVSI index of the eight critical lines but line 7-9 again shows the critical value near to one. Figure 9 shows the location of UPFC on line 2-4 improve the FVSI index of the eight critical lines but line 7-9 again shows the critical values near to one. Figure 10 shows that the location of UPFC on line 5-4 improve the FVSI index of the eight critical lines but line 3-4 again shows the critical value near to one.Figure11 shows the location of UPFC on line 2-5 improve the FVSI index of the eight critical lines but line 3-4 again shows the critical value near to one.

\section{Conclusions}

The power system stability is increased by using the UPFC.The result tested on the IEEE-14 bus system. Eight lines were critical and make the system unstable before the use of the UPFC but when the UPFC is used, it brought the system stable. The improvement of the system stability can be obtained by different locations of UPFC. In this paper the best possible location based on FVSI Index, is line 12-13, improves the FVSI Index and makes the system stable. Thus the system stability is enhanced with the UPFC at proper location.

\section{References}

[1]. Musirin, T.K.A.Rahman, 2002 "Novel Fast voltage Stability Index (FVSI) for voltage stability analysis in power transmission system" 2002 student conference on research and development proceedings, shah alam, malasia,

[2] P.W.Sauer, R.J.Evans,and M.A. Pai, 1990, “ Maximum unconstrained load ability of power systems, ” IEEE Int. Symp. Circuits and systems vol.3, pp.1818-1821.

[3] Liu Baozhu and Li Bolong, 2008 “ A Novel Static Voltage Stability Index based on Equilibrium Solution region of Branch Power Flow ," DRPT2008 6-9 Nanjing China

[4] M. Noroozian, L. Angquist, M.Ghandhari,G. Anderson,1997, “Improving Power System Dynamics by Series- connected Facts Devices", IEEE Trans. On Power Delivery, Vol.12, No.4.

[5] M. Noroozian, L. Angquist, M.Ghandhari, 1997, "Use of UPFC for Optimal Power Flow Control”, IEEE Trans. On power Delivery, Vol.12, No .4.

[6] I. Musirin, T.K.Abdul Rahman, 2002, "Estimating Maximum Loadability for Weak Bus identification using FVSI", IEEE Power Engineering Review, pp. 50 - 52.

[7] F. Milano, "PSAT, Matlab-based Power System AnalysisToolbox,"2002, available at http://thunderbox.uwaterloo.ca/_fmilano

[8] H. SAADAT, H.: Power System Analysis, Tata McGraw-Hill, 2002. 